\begin{tabular}{|c|l|}
\hline Title & Size and Stereo-specific A ccommodation of A Ikanes and A Ikenes in Calixarene based Microporous Solids \\
\hline Author(s) & Ishii, Y usuke; Nakay ama, Naoki; Konishi, Katsuaki \\
\hline Citation & $\begin{array}{l}\text { Chemistry Letters, 36(2), 246-247 } \\
\text { https://doi.org/40.1246/1.2007.246 }\end{array}$ \\
\hline Issue Date & 2007-02-05 \\
\hline Doc URL & http://hdl.handle.net/2115/49894 \\
\hline Type & article(author version) \\
\hline File Information & CL_2007_246-3.pdf \\
\hline
\end{tabular}

Instructions for use 


\title{
Size- and Stereo-specific Accommodation of Alkanes and Alkenes in Calixarene-based Microporous Solids
}

\author{
Yusuke Ishii, Naoki Nakayama, and Katsuaki Konishi* \\ Graduate School of Environmental Science and Creative Research Initiative 'Sosei', \\ Hokkaido University, North 20 West 10, Sapporo 001-0021
}

(Received November 7, 2006; CL-061307; E-mail: konishi@ees.hokudai.ac.jp)

Hydrophobic micropores created in the crystal lattice of a calix[4]arene-polyoxometalate hybrid (C2-PW) selectively accommodated heptane rather than the branched homologues. The sorption properties were tunable by slight modification of the calixarene unit, whereby the recognition of $E-Z$ stereochemistry of 2-heptene was achieved.

Porous materials have attracted continuing interests in relation to separation, storage, and catalysis technologies. ${ }^{1,2}$ Especially, shape-selective sorption of simple hydrocarbons is an important and challenging subject, but successful examples have been quite limited to date. ${ }^{3}$ We have recently reported the microporosity of an ionic crystal composed of hydrophobic calix[4] arene- $\mathrm{Na}^{+}$complex and Keggin polyoxometalate $\left((\mathrm{C} 2-\mathrm{Na})_{3}\left[\mathrm{PW}_{12} \mathrm{O}_{40}\right]\right)(\mathrm{C} 2-\mathrm{PW}$, Figure 1), and demonstrated a hydrophobic character of the pore environment in the preferential adsorption of alcohols rather than water. ${ }^{4}$ Herein we report that the micropore of C2-PW selectively accommodates linear alkane and alkene rather than the branched homologues. We also demonstrate that a subtle modification of the calixarene unit drastically affects the sorption properties, and provide an example of facile recognition of $E-Z$ stereochemistry of 2-alkene.

The calixarene components we used in addition to $\mathrm{C} 2$ are those with isopropyl (IC3) and butyl (C4) estersubstituents, from which corresponding hybrid crystals (IC3-P $\mathrm{W}, \mathrm{C} 4-\mathrm{PW})$ were prepared similarly to C2-PW. ${ }^{4}$ Powder Xray diffraction (PXRD) profiles of these crystals (S-Figure 1 in supporting information) ${ }^{5}$ were almost similar to that of $\mathrm{C} 2$ PW whose structure has been determined by single-crystal Xray crystallography (Figure 1), indicating that they also take similar packing structures with micropores.

Vapor sorption of heptanes (heptane, 2-methylhexane, 2,2-dimethylpentane) and (E)-/(Z)-2-heptenes towards C2-PW was investigated at $25^{\circ} \mathrm{C}$ (Figure 2a). ${ }^{6}$ The binding isotherms


Figure 1. Building units of porous crystals (left) and the crystal structure of C2-PW viewed along the 101 direction with hydrogen atoms and solvent molecules omitted (right). for heptane and 2-heptenes $(O, \boldsymbol{\Delta}, \boldsymbol{\nabla})$ showed clear rise at low equilibrium pressures $\left(P_{\mathrm{e}}\right)$, indicating that they were efficiently accommodated in the microchannel. ${ }^{7}$ From the PXRD profiles before and after the sorption, the original framework was essentially retained during the accommodation process. On the other hand, hindered 2methylhexane $(\mathbf{\square})$ and 2,2-dimethylpentane $(\bullet)$ were reluctant to penetrate into the pores. Thus, C2-PW selectively traps linear molecules. Since the pore opening size was estimated to be $\approx 4 \times 8 \AA$, this result is quite reasonable considering the steric bulk of the isopropyl group of 2-methylhexane and tert-

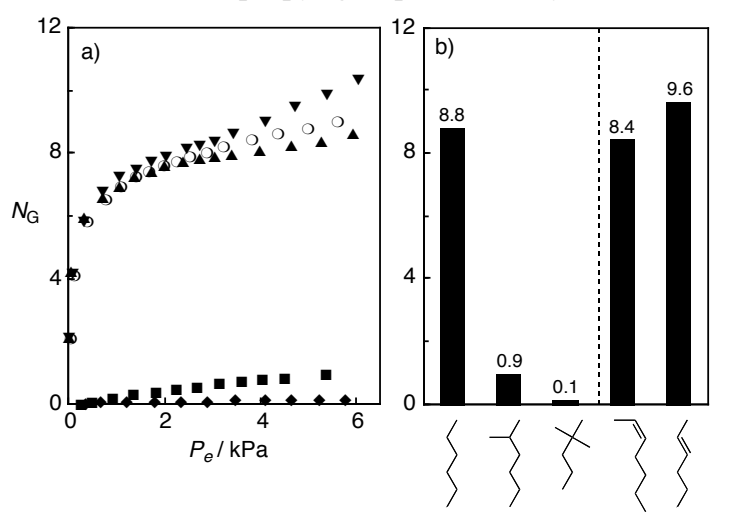

Figure 2. a) Sorption isotherms of heptane (O), 2methylhexane (四, (Z)-2-heptene $(\mathbf{\Delta}),(E)$-2-heptene $(\boldsymbol{\nabla})$ $\left(25{ }^{\circ} \mathrm{C}\right)$ and 2,2-dimethylpentane $(\bullet)\left(20{ }^{\circ} \mathrm{C}\right)$ to $\mathrm{C} 2$-PW. Plots of the number of guest molecules trapped in a single unit cell $\left(N_{\mathrm{G}}\right)$ versus $P_{\mathrm{e}}$. b) $N_{\mathrm{G}}$ at $P_{\mathrm{e}}=5 \mathrm{kPa}$.

butyl group of 2,2-dimethylpentane.

The efficient uptake of heptane and 2-heptenes, thus observed, was considered driven primarily by the attractive van der Waals and/or $\mathrm{CH}^{\cdots} \pi$ interaction of the guest alkyl chains with the hydrophobic pore surface. Actually, negligible accommodations of $\mathrm{N}_{2}$ and Ar were observed at $196{ }^{\circ} \mathrm{C}$ and $25^{\circ} \mathrm{C}$ with high pressure (up to $5 \mathrm{MPa}$ ), despite their small molecular sizes (S-Figure 2 in supporting information). ${ }^{5}$ The important role of the weak interaction involving alkyl chains was further supported by the sorption profile of methane: The binding isotherm was characteristic of the accommodation in the pore but the $P_{\mathrm{e}}$ required for saturation $(\approx 2 \mathrm{MPa})$ was much higher than those of heptane and 2-heptenes $(\approx 4 \mathrm{kPa}$, Figure $2 \mathrm{a})$.

The interaction involving the alkyl chains was further investigated by means of IR spectroscopy. The C-H stretching vibration bands of free heptane at 2967, 2931, and $2872 \mathrm{~cm}^{-1}$ (Figure 3a (i)) showed remarkable shifts to lower energies (2952, 2921 and $\left.2853 \mathrm{~cm}^{-1}\right)$ after being trapped in the pores of C2-PW (ii). Such shifts have been reported when 
long alkyl chains were closely packed via alkyl-alkyl van der Waals force. ${ }^{8}$ Therefore, considering also the absence of complimentary long alkyl chains in the pore surface, it is suggested that the attractive interaction between guest alkyl chains is one of the important factors for the efficient accommodation of linear molecules.

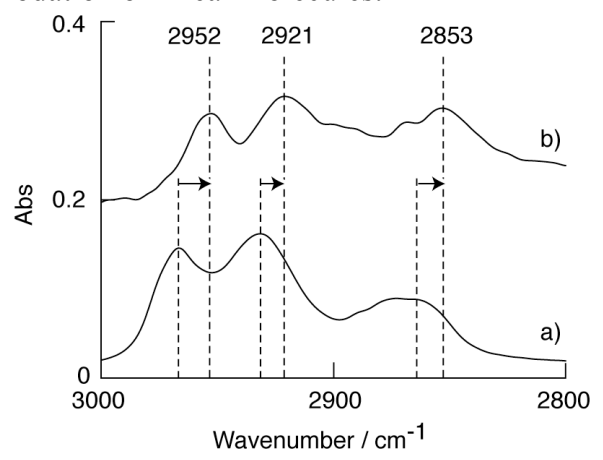

Figure 3. IR spectra ( $\mathrm{KBr}$ pellet) of (a) heptane and (b) heptane trapped by $\mathrm{C} 2-\mathrm{PW}$. For (b), the spectrum of $\mathrm{C} 2-$ $\mathrm{PW}$ was subtracted from the raw spectrum.

As we have shown, C2-PW accommodates linear alkane via weak attractive interaction. Since several ethyl ester groups of $\mathrm{C} 2-\mathrm{PW}$ are extended to lie on the pore wall, the sorption properties would be affected by the steric bulk of ester substituents. Actually, when the ethyl esters of C2-PW were replaced with butyl esters (C4-PW), the amount of trapped heptane was significantly dropped (Figure 2a vs. 4a, O). On the other hand, IC3-PW derived from calixarene with isopropyl esters sorbed heptane similarly to C2-PW (Figure $4 \mathrm{~b}, \mathrm{O})$, implying that the guest molecule can avoid the steric bulk at the pore edge due to its conformational flexibility.

The sorption isotherms in Figure 2 show that C2-PW has apparently similar affinities to heptane and 2-heptenes. However, evident differences were found in DubininRadushkevuch potential energies estimated from the initial stage of the sorption (S-Figure 3 in supporting information). ${ }^{5,9}$ The energies for the sorption of 2-heptenes (14.0 and 13.0 $\mathrm{kJ} / \mathrm{mol}$ for $(Z)$ and $(E)$-isomers, respectively) were definitely larger than that of heptane $(11.6 \mathrm{~kJ} / \mathrm{mol})$, suggesting the involvement of additional interaction associated with the olefinic $\pi$-functionality $(\mathrm{C}-\mathrm{H} \cdots \pi, \pi-\pi)$. The preference for alkenes was observed in the adsorption isotherms towards $\mathrm{C} 4-$ $\mathrm{PW}$, where nearly perfect selectivity was achieved (Figure $4 \mathrm{a}$, $\boldsymbol{\Delta}, \boldsymbol{\nabla}$ vs. O).

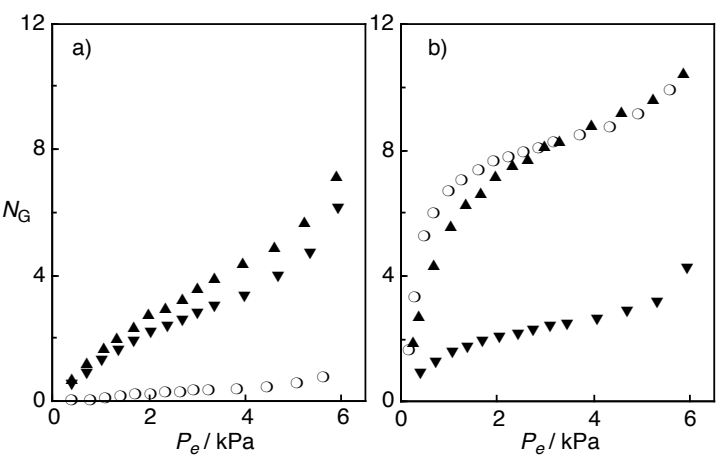

Figure 4. Sorption isotherms of heptane $(O),(Z)$-2-heptene $(\boldsymbol{\Delta}),(E)$-2-heptene $(\boldsymbol{\nabla})$ to (a) C4-PW and (b) IC3-PW at $25^{\circ} \mathrm{C}$.
On the other hand, the difference in the potential energies of $(Z)$ - and $(E)$-2-heptenes suggested that analogous materials can potentially recognize the stereochemistry of 2heptene in adsorption. When C4-PW was used as the sorbent, the amount of trapped $(Z)$-isomer was only slightly larger than that of $(E)$-isomer (Figure 4a, $\boldsymbol{\Delta}$ vs. $\boldsymbol{\nabla}$ ). In contrast, when IC3-PW was employed, the preference for $(Z)$-isomer was notably pronounced. When going from C2-PW to IC3-PW, a significant drop of the uptake was observed only for $(E)$ isomer (Figures $2 \mathrm{a}$ and $4 \mathrm{~b}, \boldsymbol{\nabla}$ ), where the amount of sorbed $(Z)$-isomer was approximately four times larger than that for (E)-isomer at $P_{\mathrm{e}}=5 \mathrm{kPa}$ (Figure $4 \mathrm{~b}, \boldsymbol{\Delta}$ vs. $\boldsymbol{\nabla}$ ). This selectivity may result from the steric repulsion between the rigid isopropyl group located at the pore edge and geometrically restricted olefinic moiety of $(E)$-isomer.

In conclusion, we have shown that the calix[4]arenebased crystals provide tunable hydrophobic micropores for the facile recognition of the shape of simple alkanes and alkenes.

This work was supported by a Grant-in-Aid for Scientific Research on Priority Area of "Chemistry of Coordination Space" from Ministry of Education, Culture, Sports, Science and Technology, Japan. The authors thank Mr. Y. Senga and Mr. T. Takagi of Nippon Bel Co. for the measurement of high-pressure gas sorption. Y. I. thanks financial supports from JSPS.

\section{References and Notes}

1 S. Kitagawa, S. Noro, T. Nakamura, Chem. Commun. 2006, 701; M. E. Davis, Nature 2002, 417, 813; O. M. Yaghi, H. Li, C. Davis, D. Richardson, T. L. Groy, Acc. Chem. Res. 1998, 31, 474.

2 Selected examples: R. Kawamoto, S. Uchida, N. Mizuno, J. Am. Chem. Soc. 2005, 127, 10560; A. C. Sudik, A. R. Millward, N. W. Ockwig, A. P. Côté, J. Kim, O. M. Yaghi, J. Am. Chem. Soc. 2005, 127, 71; R. Matsuda, R. Kitaura, S. Kitagawa, Y. Kubota, R. V. Belosludov, T. C. Kobayashi, H. Sakamoto, T. Chiba, M. Takata, Y. Kawazoe, Y. Mita, Nature, 2005, 436, 238; S. Uchida, R. Kawamoto, N. Mizuno, Inorg. Chem. 2006, 45, 5136; T. Uemura, R. Kitaura, Y. Ohta, M. Nagaoka, S. Kitagawa, Angew. Chem. Int. Ed. 2006, 45, 4112.

3 I. J. F. Denayer, W. Souverijns, P. A. Jacobs, J. A. Martens, G. V. Baron. J. Phys. Chem. B. 1998, 102, 4588; D. H. Olson, M. A. Camblor, L. A. Villaescusa, G. H. Kuehl, Microporous Mesoporous Mater. 2004, 67, 27; L. Pan, D. H. Olson, L. R. Ciemnolonski, R. Heddy, J. Li, Angew. Chem. Int. Ed. 2006, 45, 616; B. Chen, C. Liang, J. Yang, D. S. Contreras, Y. L. Clancy, E. B. Lobkovsky, O. M. Yaghi, S. Dai, Angew. Chem. Int. Ed. 2006, 45, 1390; T. J. Taylor, V. I. Bakhmutov, F. P. Gabbaï, Angew. Chem. Int. Ed. 2006, 45, 7030.

4 Y. Ishii, Y. Takenaka, K. Konishi, Angew. Chem. Int. Ed. 2004, 43, 2702.

5 Supporting information is available electronically on the CSJJournal web site, http://www.csj.jp/journals/chem-lett.

6 Saturated vapor pressures: heptane, $6.10 \mathrm{kPa}\left(25^{\circ} \mathrm{C}\right) ; 2$ methylhexane, $8.79 \mathrm{kPa}\left(25^{\circ} \mathrm{C}\right) ; 2,2$-dimethylpentane, $11.2 \mathrm{kPa}$ $\left(20^{\circ} \mathrm{C}\right) ;(E)$-2-heptene, $6.56 \mathrm{kPa}\left(25^{\circ} \mathrm{C}\right) ;(Z)$-2-heptene, 6.45 $\mathrm{kPa}\left(25^{\circ} \mathrm{C}\right)$.

7 S. J. Gregg, K. S. W. Sing, Adsorption, Surface Area and Porosity, Academic Press: London, UK, 1982.

8 M. J. Hostetler, J. J. Stocks, R. W. Murray, Langmuir 1996, 12, 3604 and references cited therein.

9 B. P. Bering, M. M. Dubinin, V. V. Serpinsky, J. Colloid Interface Sci. 1966. 21. 378. 
The diagram is acceptable in a colored form. Publication of the colored G.A. is free of charge.

For publication, electronic data of the colored G.A. should be submitted. Preferred data format is EPS, PS, CDX, PPT, and TIFF.

If the data of your G.A. is "bit-mapped image" data (not "vector data"), note that its print-resolution should be $300 \mathrm{dpi}$.

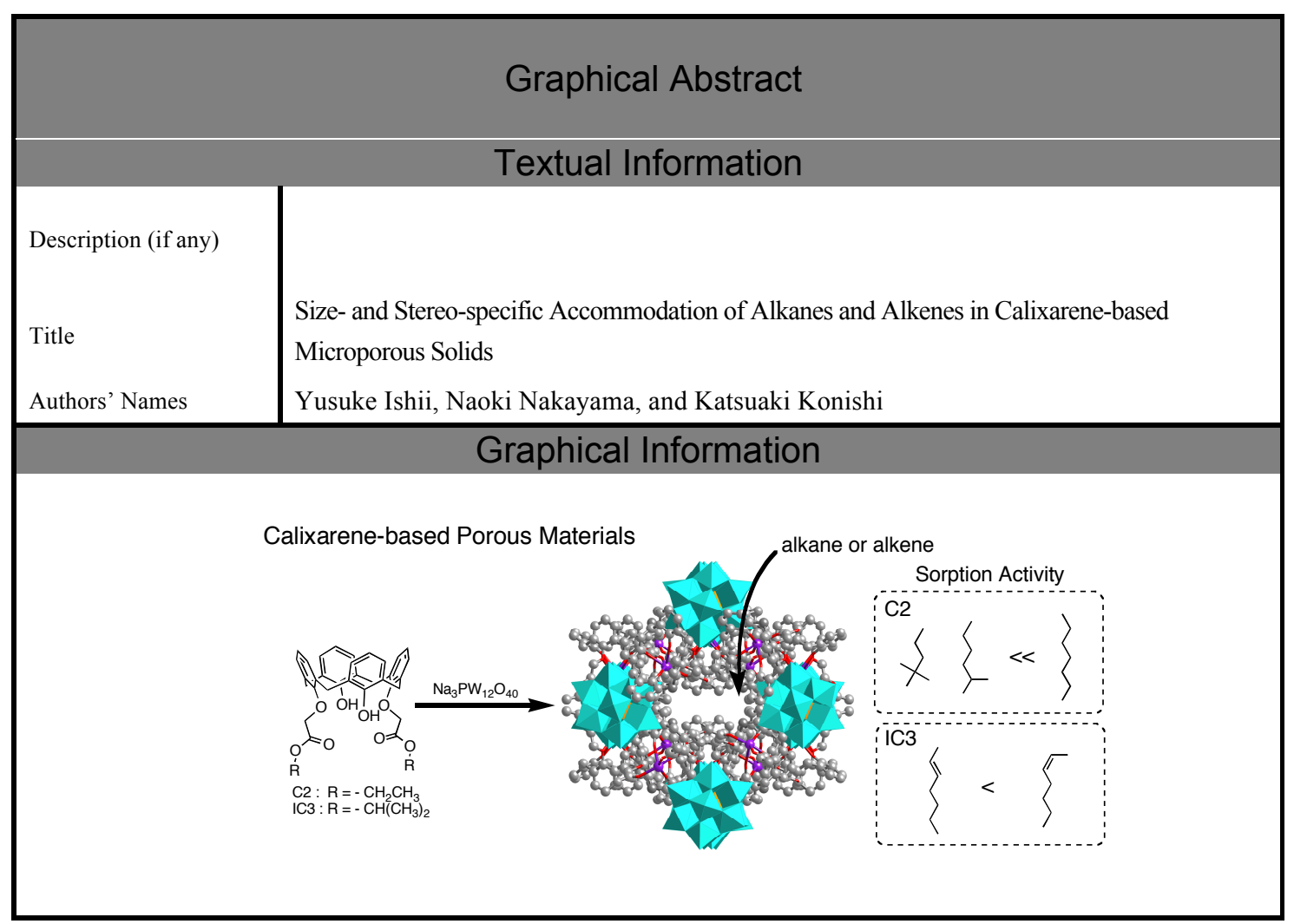

